\title{
Alternating antipyretics in the treatment of fever in children: a systematic review of randomized clinical trials
}

\author{
Gracian Li Pereira, ${ }^{1}$ Josiane Magda Camarotto Dagostini, ${ }^{2}$ Tatiane da Silva Dal Pizzol ${ }^{3}$
}

\begin{abstract}
Objective: To summarize the existing evidence on the efficacy of therapy with alternating antipyretics compared to monotherapy in the management of fever in children.

Sources: MEDLINE, EMBASE, Cochrane Library, LILACS, SciELO, IBECS, Web of Science, Clinical Trials, Google Scholar and references of the articles found. The review included randomized clinical trials published until December 2011 , in which one of the arms was the alternating antipyretics therapy to treat fever in children younger than 12 years, treated on an outpatient basis. Data selection and extraction were performed independently by two reviewers. The quality of the studies was assessed according to CONSORT items.

Summary of the findings: The selected studies showed great heterogeneity of participants, temperature for fever diagnosis, interventions (dose and dosing intervals) and assessed outcomes. The treatment groups ranged from 38 to 464 children. The studies compared paracetamol and ibuprofen alternated with paracetamol and/or ibuprofen. Only one study used different doses from the $15 \mathrm{mg} / \mathrm{kg}$ for paracetamol and $10 \mathrm{mg} / \mathrm{kg}$ for ibuprofen, but the dosing intervals varied considerably. The alternate use with dipyrone or acetylsalicylic acid was not assessed by any of the studies. Overall, the articles pointed to a tendency of lower mean temperatures in groups with alternating therapy. Few adverse effects were reported.

Conclusion: Although there was a tendency towards the reduction of mean temperatures with alternating antipyretics compared to the use of one antipyretic alone, there is not enough evidence to say that alternating antipyretic therapy is more effective than monotherapy.
\end{abstract}

J Pediatr (Rio J). 2012;88(4):289-96: Fever, children, antipyretics, efficacy, alternating therapy, review.

\section{Introduction}

Although fever is a normal adaptive process with some advantages in important outcomes in animal models, 1,2 parents' fear of febrile seizure, brain damage, or even death, cause fever to be one of the most common causes for pediatric care demands (from 25 to $40 \%$ of consultations), ${ }^{3}$ often after the child has been medicated at home. ${ }^{4}$ Although antipyretic therapy does not seem to reduce the chance of a febrile seizure, which, in most cases, is benign, the aggressive management of this signal is common. Studies conducted in Argentina, USA, Spain and Australia verified that the alternate use of antipyretics ranged from 51 to $61 \%$, and that 59 to $97 \%$ of pediatricians, in these countries, recommended the alternating regimen of antipyretics. ${ }^{5-8}$

1. MSc in Epidemiology, Faculdade de Medicina, Universidade Federal do Rio Grande do Sul (UFRGS), Porto Alegre, RS, Brazil.

2. Resident physician, Serviço de Cardiologia Pediátrica, Hospital Pequeno Príncipe, Curitiba, PR, Brazil.

3. PhD in Epidemiology. Professor, Programa de Pós-Graduação em Epidemiologia, Faculdade de Medicina, UFRGS, Porto Alegre, RS, Brazil.

No conflicts of interest declared concerning the publication of this article.

Suggested citation: Pereira GL, Dagostini JM, Dal Pizzol Tda S. Alternating antipyretics in the treatment of fever in children: a systematic review of randomized clinical trials. J Pediatr (Rio J). 2012;88(4):289-96.

Manuscript submitted Mar 31 2012, accepted for publication Apr 102012.

http://dx.doi.org/10.2223/JPED.2204 
The establishment of an alternating therapy is usually indicated so that one drug is acting while another is in the descending curve, preventing the temperature to rise again when the time for the next dose approaches. According to concentration curves versus temperature difference of ibuprofen and paracetamol in children, this principle is plausible, ${ }^{9,10}$ justifying its use in this scheme for, theoretically, maintaining the child with normal temperature for a longer period of time.

Efficacy and safety of ibuprofen and paracetamol used alone in the treatment of fever in children are well established. ${ }^{11}$ In meta-analysis conducted by Perrott et al., 12 it was verified that ibuprofen was more effective as an antipyretic than paracetamol, producing lower temperatures 2, 4 and 6 hours after treatment. There does not seem to be any difference among medications regarding safety of use. In Brazil, besides paracetamol and ibuprofen, acetylsalicylic acid is also used and, especially, dipyrone. Although dipyrone is not used in the USA, it is freely commercialized in other regions of the world, such as Latin America, Europe, Africa and Asia. Some studies on the efficacy of dipyrone in the treatment of fever in children have been reported. 3,13-15 It is known that the use of dipyrone is associated with the risk of blood dyscrasias, but in populations where its use is released, as in Brazil, agranulocytosis rates are as low as in populations where dipyrone was banned, suggesting a possible genetic propensity for the occurrence of the adverse effect. ${ }^{16,17}$

The objective of this systematic review was to summarize the findings of randomized clinical trials comparing the efficacy of the alternate use of antipyretics commonly used in Brazil with the use of monotherapy for treating fever in children.

\section{Methods \\ Study protocol}

A research protocol has been designed to guide the implementation of all steps of the systematic review, which is available from the authors.

\section{Inclusion criteria}

The studies which presented the following characteristics were considered eligible: (1) randomized controlled trials, open or blinded; (2) one of the arms of therapy consisting of alternating antipyretics for fever treatment in outpatient care; (3) children aged 12 or less; and (4) available data to measure the effect of therapy, such as mean difference in temperature among the groups.

\section{Data source}

Electronic searches were performed looking for articles published until December 2011 in the following databases: MEDLINE, EMBASE, registration of clinical trials of Cochrane
Library, LILACS, SciELO, IBECS, Web of Science, Clinical Trials and Google Scholar. The search for dissertations, thesis, and conference annals was conducted by Google Scholar. There was no restriction on language or publication year. The list of return of each search was compiled into one single list of abstracts, and duplicate entries were removed.

\section{Search strategy}

The search strategy was developed having MEDLINE as reference, using the following keywords: (fever) AND (antipyretic) AND (child) AND (alternated) AND randomized controlled trial [Publication type] OR randomized[Title/ Abstract] OR (random*). When necessary, the strategy was adapted to each database.

\section{Selection of studies}

Eligibility criteria were applied to all titles and abstracts, by two reviewers (GLP, JMCD). Cases of disagreement were discussed by reviewers until they reached a consensus. The references of the selected studies were accessed as a source of new references.

\section{Data extraction}

Data from the selected articles were extracted independently by two researchers (GLP, JMCD) and organized into a pre-established form. Cases of disagreement were solved by consensus. The researchers were not blinded for journal and authors. Authors of the studies were contacted in case of uncertainty or in the absence of specific data.

The following items were collected: participants characteristics, diagnostic measures of fever, characteristics of the compared groups (drug, dose, dosing interval, route of administration and length of intervention), funding by the pharmaceutical industry, and aspects of methodological quality. Reduction in body temperature was the primary outcome chosen to test effectiveness of the treatments. Other ways to measure the benefits (stress scale, recurrent fever, visits to the emergency rooms) were also described when found. Adverse effects of treatments were analyzed as secondary outcome.

\section{Quality assessment}

The quality of the articles was assessed according to the CONSORT18,19 items, ranked by reviewers as being of high or low quality.

\section{Measures-summary}

The main measure of the effect of treatment was the mean difference in body temperature among the compared groups. Data on the mean temperatures in the first 8 hours of treatment were obtained after contacting the authors, when not available in the article. 


\section{Results synthesis}

Due to the small number of clinical trials and the great heterogeneity across them, data from individual studies were assessed qualitatively, without using meta-analysis.

The guidelines Preferred Reporting Items for Systematic Reviews and Meta-Analyses (PRISMA) were followed for the preparation of this systematic review. ${ }^{20}$

\section{Results}

Of a total of 1,018 references located in nine databases, 986 remained for analysis, after removal of duplicate references. Of these references, 12 were initially included, from the reading of the abstract. After exclusion of four studies that did not meet the inclusion criteria (2) or which were not finished (2), eight articles remained. After full reading of the articles, another four were excluded, because they had different populations or interventions from the eligibility criteria. The process of selection of the studies can be seen in Figure 1.

Characteristics of the four clinical trials that met the inclusion criteria21-24 are summarized in Table 1. Participants, interventions (dose, dosing interval, duration) and outcome measures used in the studies are heterogeneous, making it impossible to perform meta-analysis.

\section{Characteristics of the studies}

\section{Participants}

The total number of participants in each study ranged from $38^{24}$ to 464 children. ${ }^{21}$ Children from 6 months old until 8 years, from the USA, ${ }^{22,24}$ England $^{23}$ and Israel, ${ }^{21}$ in outpatient care or in need of observation in day care, ${ }^{24}$ at most. In two studies, children who took antibiotics ${ }^{21}$ and/or antipyretics 21,22 in the last 4 to 8 hours were excluded.

\section{Diagnosis of fever}

The diagnostic cutoff values for fever ranged from $37.8^{23}$ to $38.4{ }^{\circ} \mathrm{C}_{1}{ }^{21}$ measured via rectal, ${ }^{21,22}$ oral, $^{22}$ axillar, $^{23}$ or temporal artery ${ }^{24}$ route. Hay et al. ${ }^{23}$ used a device connected to an axillary probe which registered the temperature of the child electronically every 30 seconds during the first 24 hours of the study, using axillar thermometry for 4, 16, 24, 48 hours and in the 5th day of antipyretic treatment.

\section{Interventions}

In all studies, the alternating treatment investigated included ibuprofen and paracetamol. One study showed a single group for comparison with paracetamol alone. ${ }^{22}$ Sarrell et al. ${ }^{21}$ and Hay et al. ${ }^{23}$ compared the alternating regimen (group C) with paracetamol alone (group A) and ibuprofen alone (group B). Paul et al. ${ }^{24}$ compared ibuprofen alone (group A) versus ibuprofen and paracetamol administered simultaneously (group B) and ibuprofen and paracetamol alternated (group C). Sarrell et al. ${ }^{21}$ used different dosing from the $15 \mathrm{mg} / \mathrm{kg} /$ dose paracetamol and $10 \mathrm{mg} / \mathrm{kg} /$ dose ibuprofen.

Intervals between doses varied; for antipyretics used alone, the administration occurred every 4 to 6 hours for paracetamol and single dose or every 8 hours for ibuprofen. For the alternating scheme, Sarrell et al. ${ }^{21}$ maintained the dosing interval fixed in 4 hours, but the doses or number of administrations varied. In two studies, ${ }^{22,24}$ a dosing interval of 3 hours was used. Hay et al. ${ }^{23}$ maintained the medications with their usual dosing intervals ( 4 to 6 hours

\section{1,018 references found:}

- Google Scholar: 977

- MEDLINE/PubMed: 11

- EMBASE: 14

- Cochrane Library: 1

- LILACS, SCIELO, IBECS: 0

- Web of Science: 13

- Clinical Trials: 2

986 references analyzed after removal of duplicates

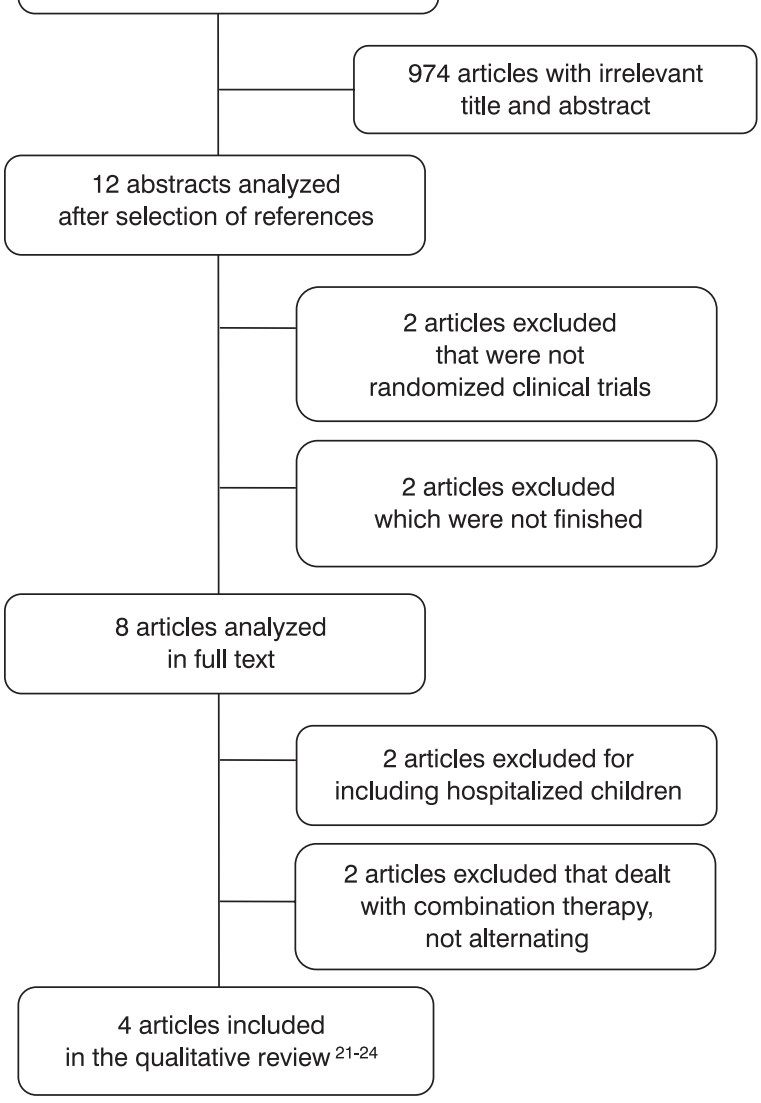

Figure 1 - Flowchart of the process of selection of articles 





for paracetamol and 6 to 8 hours for ibuprofen), leaving for the discretion of parents the administration of the next dose after the first 24 hours of treatment, criterion also used by Sarrell et al. ${ }^{21}$ after the initial dose of the study.

\section{Primary outcome}

In three studies, the primary outcome analyzed was the mean difference in temperature among groups at different intervals, measured in hours 22,24 or days. ${ }^{21}$ One of the studies ${ }^{23}$ presented its as primary outcome the time without fever, but data on mean difference in temperature were obtained after contact with the author. Sarrell et al. ${ }^{21}$ obtained lower mean of temperature in the group of alternate therapy on days 1 , 2 e 3, when compared to paracetamol alone $(p<0.001)$ and ibuprofen alone $(p<0.001)$, with greater differences in mean temperature among the groups (up to $1.1^{\circ} \mathrm{C}$ between ibuprofen alone and alternating therapy on day 3 ), but no mean temperature below $37.8^{\circ} \mathrm{C}$ in the three groups compared.

Kramer et al. ${ }^{22}$ found a statistically significant difference between the alternating therapy and paracetamol after $4(p=0.05)$ and 5 hours $(p=0.003)$ of the first dose, whose mean absolute differences in degrees were 0.6 and $0.8^{\circ} \mathrm{C}$, in the 4th and 5th hour, respectively. In the sixth hour, the mean absolute difference was $0.1^{\circ} \mathrm{C}(\mathrm{p}>0.05)$. Hay et al. ${ }^{23}$ used the time without fever in the first 4 hours after the first dose as primary outcome (the child whose temperature was below $37.2^{\circ} \mathrm{C}$ was considered afebrile), demonstrating longer time without fever in the group with alternating therapy than in the other groups (171.1 minutes for alternating therapy, 156 minutes for ibuprofen and 116.2 minutes for paracetamol) ( $p<0.001)$. Paul et al. ${ }^{24}$ verified lower mean temperature in the alternate therapy group when compared to the group which received ibuprofen alone after $4(p=0.003), 5(p<0.001)$ and 6 hours $(p<0.001)$ from baseline.

Mean temperatures in the first 8 hours of treatment for the comparison groups were presented in Figure 2. Sarrell et al. ${ }^{21}$ did not measure the evolution of the thermal curve in this period of time, so there are no data to plot on the graph.

\section{Secondary outcomes}

Sarrell et al. ${ }^{21}$ measured the recurrence of fever on days 5 and 10 after baseline and found differences among the groups only on the fifth day $(p=0.02)$, besides lower number of absences in the nursery school in the group with alternate therapy $(p<0.001)$. There was no difference among the groups regarding the number of visits to the emergency room after the beginning of the study. Other outcomes assessed were the differences in the pain checklist in non-communicative children and the amount of medication used on the 3 days of study, showing a difference of lower
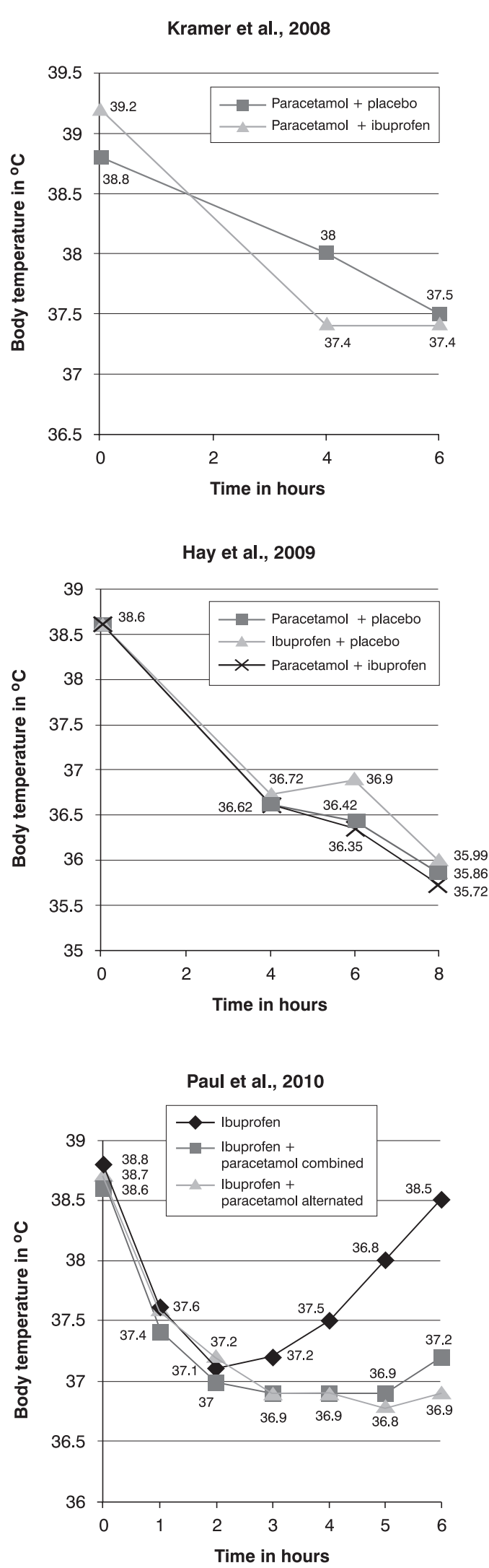

Figure 2 - Temperatures in the first 8 hours of treatment, by intervention group, in three clinical trials included in the systematic review. There were no data available on the study of Sarrell et al. ${ }^{21}$ to plot a graph of temperature for the first 8 hours of treatment. 
scores on the scale and reduced use of medication for the group of alternated therapy, when compared to monotherapy $(p<0.001)$

Hay et al. ${ }^{23}$ measured the proportion of children without discomfort rated by parents through scale in the first 48 hours, finding no differences among groups. However, the sample power was insufficient for this outcome. Until the first afebrile moment, there was difference favoring the alternate therapy and ibuprofen alone when compared to paracetamol alone $(p=0.025$ for alternate therapy versus paracetamol alone and $p=0.015$ for ibuprofen alone versus paracetamol alone), and alternate therapy versus ibuprofen did not show any significant difference. The absolute difference among the groups with significant difference was around 25 minutes. Another secondary outcome evaluated was the time without fever in the first 24 hours. Alternating therapy showed greater time without fever compared with paracetamol alone $(p<0.001)$ and isolated ibuprofen $(p=0.008)$. The absolute difference between the groups with significant difference ranged from 4.4 to 2.5 hours.

In the study by Paul et al.24, the group that received alternating therapy had all patients without fever from the 2 nd hour of observation until the 6 th hour, while the group receiving isolated ibuprofen was never completely afebrile, showing statistical difference in hour $4(p=0.002)$, $5(p<0.001)$ and $6(p<0.001)$. Kramer et al. did not present data on secondary outcome. ${ }^{22}$

\section{Adverse events}

One study has not verified the occurrence of adverse effects. ${ }^{24}$ None of the studies reported serious adverse effects. Sarrell et al. ${ }^{21}$ found no differences among the groups for markers of liver or renal failure; no patient with altered enzyme dosage in the acute phase (measured on days 3 and 5) persisted with high levels after day 14 . Kramer et al. ${ }^{22}$ found no difference among groups in the occurrence of mild adverse effects, such as diarrhea, flatulence, nausea, vomiting, inappetence, epigastric pain, headache and insomnia. Diarrhea and vomiting were the main adverse effects reported by Hay et al., ${ }^{23}$ appearing equally distributed among the groups. Five children participating in the study were hospitalized, but there was no relationship between the cause of hospitalization and the treatment used in the study. ${ }^{23}$

\section{Discussion}

The present systematic review summarized the literature on the use of therapy with alternating antipyretics to treat fever in children in outpatient settings, showing that there is not enough evidence to support the use of these schemes of administration in the treatment of fever, although the design of clinical trials was satisfactory, according to the
CONSORT criteria. Our conclusion was in line with the findings of two reviews on alternating or combination therapy (simultaneous administration of two drugs) with paracetamol and ibuprofen, 25,26 adding worrying data regarding the absence of evidence related to the efficacy of alternating therapy with other antipyretics of common use in Brazil, particularly dipyrone and acetylsalicylic acid. 27,28 Moreover, important aspects of the methodology of systematic review were not reported in the reviews cited, such as attempts to access unpublished studies (grey literature), 25 selection of articles and extraction of duplicate data, 25,26 and limitation to the English language and the MEDLINE and EMBASE databases. ${ }^{26}$

Although there is biological plausibility for the use of the alternating antipyretic scheme to increase afebrile time in children, there is no agreement on the best standard scheme, especially regarding the interval between different drugs, and no consensus regarding the use of combining therapy - using two drugs simultaneously. ${ }^{29-32}$ With the differences in peak and duration of action among drugs, the choice of a point in the timeline where the assessment of the temperature among the therapy groups is more suitable is also difficult, and other outcome alternatives, such as comfort and stress of the children, should be considered. The heterogeneity among the administration schedules, the small sample size in each group and the short-term followup hinder the establishment of an answer regarding the safety of this practice in more serious outcomes.

The parents' fear to take part in a study for the treatment of fever makes it difficult to randomize the number of patients needed to answer the clinical question. 5,33 The reasons are numerous, resulting mainly from lack of understanding about the fever process. ${ }^{4,34}$ Some studies about the treatment of fever and febrile seizures have failed to demonstrate that aggressive therapy with antipyretics reduces the recurrence of the event ${ }^{35}$ and that the presence of fever seems to be linked only to the worsening of the patient's condition with some type of brain damage. ${ }^{36}$

Ibuprofen and paracetamol have, in general, mild adverse effects when used in recommended doses and intervals; however, there is risk of serious events, although rare, such as gastrointestinal bleeding, Steven-Johnson syndrome and hepatic or renal failure. ${ }^{37}$ Findings showing errors in dosage and dosing intervals of these medications by parents should alert for the need of education about the fever process and the rational use of antipyretic therapy. 5,8 One should be aware of the fact that the difference in average temperature during the first 6 hours of treatment, in this review, is limited to justify the use of two drugs, adding potential adverse effects, in a condition where the choice of treating or not remains controversial.2,26,36

This review in not free of publication bias. Although we found studies that cannot be considered definitive in answering our clinical question, all of them report a 
trend towards a better performance of the alternating therapy group, even if the outcome chosen by the authors, temperature, is a secondary marker of the patient's wellbeing. No article with negative outcomes, or even negative trends, was found. Furthermore, the researchers were not blinded during the selection of articles or data extraction. Although Jadad et al. ${ }^{38}$ suggest that blind assessments produce lower and more consistent scores, other studies 39,40 showed little benefit, besides the fact that blinding is arduous and useless when the researchers are familiar with the subject.

We found no definitive evidence to support the alternate use of antipyretics for outpatient treatment of fever in children. The existing uncertainty about the aggressive treatment of fever still requires clinical trials that assess not only how many degrees the temperature decreases in each group, but also the impact of this therapy in the patient's well-being, mainly related to morbidity/mortality. These results can only be obtained with longer studies, provided with a larger sample size and that include other antipyretics of widespread use in Brazil and other countries, such as dipyrone.

\section{References}

1. Jiang Q, Cross AS, Singh IS, Chen TT, Viscardi RM, Hasday JD. Febrile core temperature is essential for optimal host defense in bacterial peritonitis. Infect Immun. 2000;68:1265-70.

2. El-Radhi AS. Why is the evidence not affecting the practice of fever management? Arch Dis Child. 2008;93:918-20.

3. Wong A, Sibbald A, Ferrero F, Plager M, Santolaya ME, Escobar $A M$, et al. Antipyretic effects of dipyrone versus ibuprofen versus acetaminophen in children: results of a multinational, randomized, modified double-blind study. Clin Pediatr (Phila). 2001;40:313-24.

4. Purssell E. Parental fever phobia and its evolutionary correlates. J Clin Nurs. 2009;18:210-8.

5. Wright $A D$, Liebelt EL. Alternating antipyretics for fever reduction in children: an unfounded practice passed down to parents from pediatricians. Clin Pediatr (Phila). 2007;46:146-50.

6. Melamud A, Suwezda A, Matamoros R, Ringuelet L. Antipyretics indication by pediatricians. Internet as a tool in data collections. Arch Argent Pediatr. 2008;106:404-8.

7. Díez Domingo J, Burgos Ramírez A, Garrido García J, Ballester Sanz A, Moreno Carretero E. Use of alternating antipyretics in the treatment of fever in Spain. An Esp Pediatr. 2001;55:503-10.

8. Walsh A, Edwards H, Fraser J. Parents' childhood fever management: community survey and instrument development. J Adv Nurs. 2008;63:376-88.

9. Brown RD, Kearns GL, Wilson JT. Integrated pharmacokineticpharmacodynamic model for acetaminophen, ibuprofen, and placebo antipyresis in children. J Pharmacokinet Biopharm. 1998;26:559-79.

10. Kelley MT, Walson PD, Edge JH, Cox S, Mortensen ME. Pharmacokinetics and pharmacodynamics of ibuprofen isomers and acetaminophen in febrile children. Clin Pharmacol Ther. 1992; 52:181-9.

11. Purssell E. Treating fever in children: paracetamol or ibuprofen? $\mathrm{Br}$ J Community Nurs. 2002; 7:316-20.
12. Perrott DA, Piira T, Goodenough B, Champion GD. Efficacy and safety of acetaminophen vs ibuprofen for treating children's pain or fever: a meta-analysis. Arch Pediatr Adolesc Med. 2004;158:521-6.

13. Gozzoli V, Treggiari MM, Kleger GR, Roux-Lombard P, Fathi M, Pichard C, et al. Randomized trial of the effect of antipyresis by metamizol, propacetamol or external cooling on metabolism, hemodynamics and inflammatory response. Intensive Care Med. 2004;30:401-7.

14. Lell $B$, Sovric M, Schmid D, Luckner D, Herbich $K$, Long HY, et al. Effect of antipyretic drugs in children with malaria. Clin Infect Dis. 2001;32:838-41.

15. Yilmaz HL, Alparslan N, Yildizdas D, Bayram I, Alhan E. Intramuscular dipyrone versus oral ibuprofen or nimesulide for reduction of fever in the outpatient setting. Clin Drug Investig. 2003;23:519-26.

16. Andrade SE, Martinez C, Walker AM. Comparative safety evaluation of non-narcotic analgesics. J Clin Epidemiol. 1998;51:1357-65.

17. Hamerschlak N, Maluf E, Biasi Cavalcanti A, Avezum Júnior $A$, Eluf-Neto J, Passeto Falcão R, et al. Incidence and risk factors for agranulocytosis in Latin American countries-the Latin Study: a multicenter study. Eur J Clin Pharmacol. 2008;64:921-9.

18 Ioannidis JP, Evans SJ, Gøtzsche PC, O'Neill RT, Altman DG, Schulz $\mathrm{K}$, et al. Better reporting of harms in randomized trials: an extension of the CONSORT statement. Ann Intern Med. 2004;141:781-8.

19. Moher D, Schulz KF, Altman DG; CONSORT GROUP (Consolidated Standards of Reporting Trials). The CONSORT statement: revised recommendations for improving the quality of reports of parallelgroup randomized trials. Ann Intern Med. 2001;134:657-62.

20. Moher D, Liberati A, Tetzlaff J, Altman DG; PRISMA Group. Preferred reporting items for systematic reviews and meta-analyses: the PRISMA statement. PLoS Med. 2009;6:e1000097.

21. Sarrell EM, Wielunsky E, Cohen HA. Antipyretic treatment in young children with fever: acetaminophen, ibuprofen, or both alternating in a randomized, double-blind study. Arch Pediatr Adolesc Med. 2006; 160:197-202.

22. Kramer LC, Richards PA, Thompson AM, Harper DP, Fairchok MP. Alternating antipyretics: antipyretic efficacy of acetaminophen versus acetaminophen alternated with ibuprofen in children. Clin Pediatr (Phila). 2008;47:907-11.

23. Hay AD, Redmond NM, Costelloe C, Montgomery AA, Fletcher M, Hollinghurst $S$, et al. Paracetamol and ibuprofen for the treatment of fever in children: the PITCH randomised controlled trial. Health Technol Assess. 2009;13:iii-iv, ix-x, 1-163.

24. Paul IM, Sturgis SA, Yang C, Engle L, Watts $H$, Berlin CM Jr. Efficacy of standard doses of Ibuprofen alone, alternating, and combined with acetaminophen for the treatment of febrile children. Clin Ther. 2010;32:2433-40.

25. Nabulsi M. Is combining or alternating antipyretic therapy more beneficial than monotherapy for febrile children? BMJ. 2009;339:b3540.

26. Purssell E. Systematic review of studies comparing combined treatment with paracetamol and ibuprofen, with either drug alone. Arch Dis Child. 2011;96:1175-9.

27. Pereira FS, Bucaretchi F, Stephan C, Cordeiro R. Self-medication in children and adolescents. J Pediatr (Rio J). 2007;83:453-8.

28. Santos DB, Clavenna A, Bonati M, Coelho HL. Off-label and unlicensed drug utilization in hospitalized children in Fortaleza, Brazil. Eur J Clin Pharmacol. 2008;64:1111-8.

29. Lal A, Gomber S, Talukdar B. Antipyretic effects of nimesulide, paracetamol and ibuprofen-paracetamol. Indian J Pediatr. 2000;67:865-70.

30. Tenison M, Eberhardt M, Pellett N, Heller M. Is the combination of ibuprofen and acetaminophen a better pediatric antipyretic than ibuprofen alone? Ann Emerg Med. 2005;46:54.

31. Erlewyn-Lajeunesse MD, Coppens K, Hunt LP, Chinnick PJ, Davies $\mathrm{P}$, Higginson IM, et al. Randomised controlled trial of combined paracetamol and ibuprofen for fever. Arch Dis Child. 2006;91:414-6. 
32. Forgione H, Grinzpan G, Monteros N, De L, Gimenez J. Evaluación clínica del efecto antitérmico de una dosis única de paracetamol, dipirona y de ambos fármacos asociados. Prensa Med Argent. 1995;82:785-90.

33. Miller AA. Alternating acetaminophen with ibuprofen for fever: is this a problem? Pediatr Ann. 2007;36:384-8.

34. Moraga FM, Horwitz BZ, Romero CS. Fiebrefobia: conocimiento y actitud de los padres respecto de la fiebre. Rev Chil Ped. 2007;78:160-4.

35. Strengell T, Uhari M, Tarkka R, Uusimaa J, Alen R, Lautala $P$, et al. Antipyretic agents for preventing recurrences of febrile seizures: randomized controlled trial. Arch Pediatr Adolesc Med. 2009;163:799-804.

36. Aiyagari V, Diringer MN. Fever control and its impact on outcomes: what is the evidence? J Neurol Sci. 2007;261:39-46.

37. DRUGDEX ${ }^{\circledR}$ System. Thomson MICROMEDEX. 2010. http://www. thomsonhc.com/home/dispatch. Access: 08/03/2012.
38. Jadad AR, Moore RA, Carroll D, Jenkinson C, Reynolds DJ, Gavaghan $D$ J, et al. Assessing the quality of reports of randomized clinical trials: is blinding necessary? Control Clin Trials. 1996;17:1-12.

39. Berlin JA. Does blinding of readers affect the results of metaanalyses? University of Pennsylvania Meta-analysis Blinding Study Group. Lancet. 1997;350:185-6.

40. Kjaergard LL, Villumsen J, Gluud C. Reported methodologic quality and discrepancies between large and small randomized trials in meta-analyses. Ann Intern Med. 2001;135:982-9.

Correspondence:

Tatiane da Silva Dal Pizzol

Rua Ramiro Barcelos, 2400, $2^{\circ}$ andar

CEP 90035-003 - Porto Alegre, RS - Brazil

Tel./Fax: +55 (51) 3308.5281

E-mail: tatiane.silva@ufrgs.br 